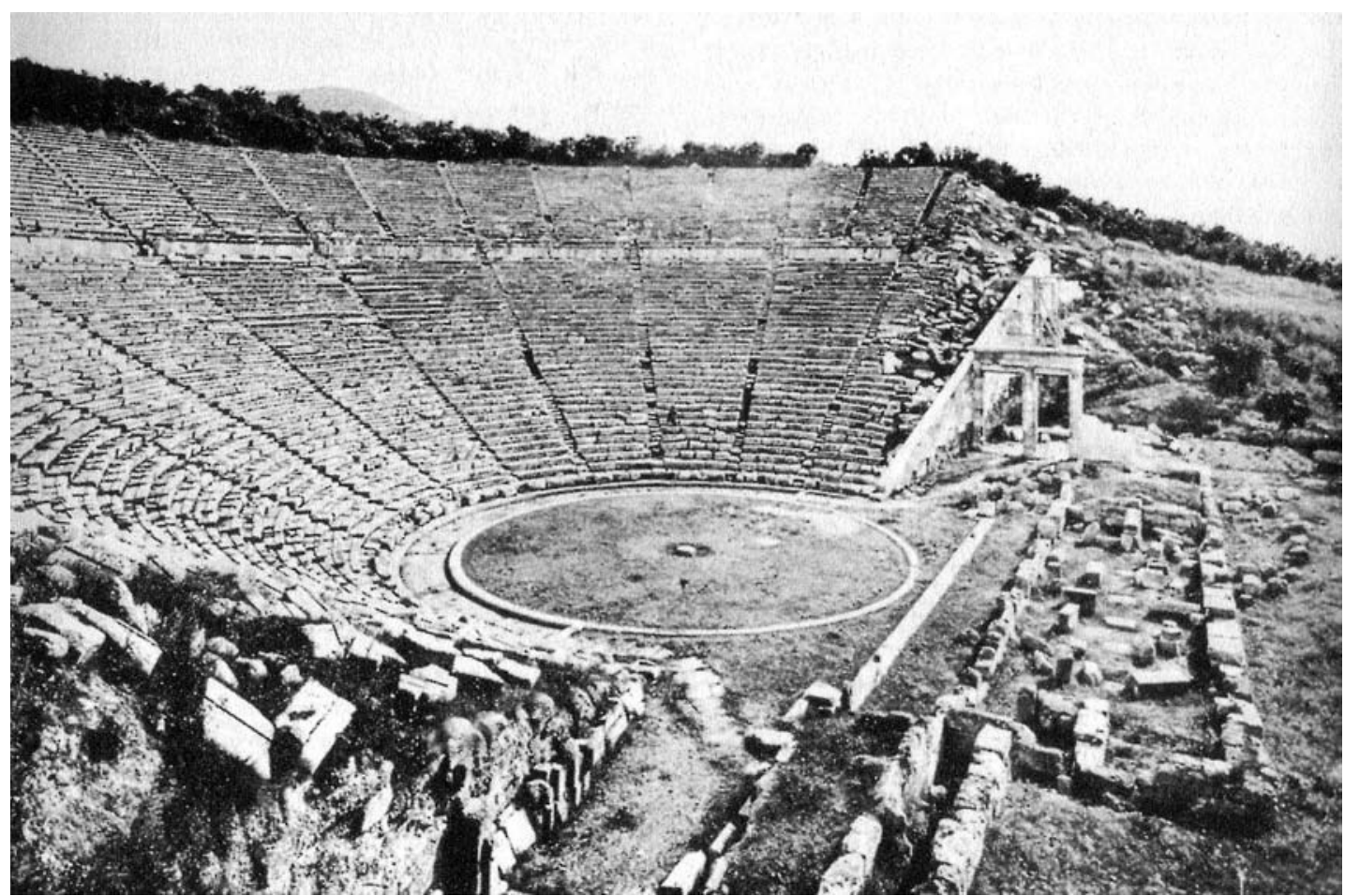

\title{
Sófocles: 2500 anos depois
}

\author{
José Pedro Serra
}

É nas pedras, caidas, dispersas, mudas, anarquicamente dispostas, ou, ao contrário, conservando ainda a harmonia da forma e o equilibrio do espaço, e também nas palavras, escritas, ou ainda audíveis no sopro de um vento antiquissimo, é assim que os anfiteatros gregos se fazem sentir e se tornam presentes. Desde a sua alvorada na já longínqua cidade-estado, a densa e imensa história destes anfiteatros guarda a memória de cerimónias políticas e militares, de rituais, de sacrificios religiosos e de procissões, de ditirambos e de representações teatrais. Desta fragmentada, mesclada e ubérrima seiva é certamente a tragédia que constitui a mais poderosa força, o sangue elementar que ainda hoje mantém bem vivo o pulsar do theatron. É comovente lançar o olhar e o gesto atrás, numa memória por dois mil e quinhentos anos estendida, e trazer uma mão tão cheia de vozes e de figuras, de mitos e destinos, de crimes, de culpas, de amores, de supremas lealdades e traições, de abissais inquietações, de severas dúvidas, de limpidas esperanças. Lembrar a tragédia, porém, não é apenas comovente - embora o seja um ser tão breve pensar em tão longa demora -, é apropriarmo-nos de um rosto, tomarmos para nós um destino, erguermo-nos como homens e coincidirmos com o nosso destino trágico.

Por estas e outras razões, a Associação Portuguesa de Estudos Clássicos, o Instituto de Estudos Clássicos e o Centro de Estudos Clássicos e Humanísticos da Universidade de Coimbra, o Departamento de Estudos Clássicos e o Centro de Estudos Clássicos da Universidade de Lisboa organizaram, entre 27 de Novembro e 11 de Dezembro últimos, um conjunto de actividades comemorativas dos 2500 anos do nascimento de Sófocles.
De entre os três grandes tragediógrafos gregos, Ésquilo, Sófocles e Eurípides, Sófocles é certamente aquele que mais imediatamente nos envolve, nos obriga a mergulhar nos dilemas das personagens, nos arrasta no tumulto das emoções desencadeadas. Esta não mais profunda, mas mais óbvia familiaridade relaciona-se com o momento político da Atenas de Sófocles e com o lugar que este ocupa na evolução da tragédia. Segundo uma antiga tradição, pouco digna de crédito, mas bastante significativa quanto à importância da vitória dos Gregos sobre os Persas, Ésquilo teria combatido em Salamina (480 a.C.), Sófocles teria dirigido o coro dos jovens que celebrou a vitória e Euripides teria nascido nesse mesmo dia e nesse local. Entre outros aspectos, esta efabulação tem a vantagem de salientar a ordenação cronológica entre os três tragediógrafos, ordenação que não é meramente formal e que corresponde a modificações de conteúdo e de intencionalidade.

Herdeiro de Ésquilo, o teatro de Sófocles, todavia, não coincide já com o momento épico-trágico da fundamentação de um novo direito e da plena instauração da democracia. A tragédia da razão emergente e da nova ordem política, de que a Oresteia é o mais incisivo desenho, corresponde em Ésquilo à saga do humano na demanda de uma nova ordem, de uma nova harmonia, de uma nova Justiça. Esta saga integra as relações familiares, os crimes e as expiações, o desejo de poder e de glória, mas o trágico assume os contornos da aventura colectiva da invenção da polis, na qual se inserem as relações entre os homens e os deuses e os daimones. Por isso pode a tragédia de Ésquilo ser vista como a tragédia dos homens inscrita na procura da compreensão da Justiça de Zeus. Sófocles não pertence já 
a este momento fundador, à alegria trágica da instauração da democracia e do Direito que a suporta. A cidade democrática triunfou e a autoridade de Atena pôde garantir a validade dos tribunais e a legitimidade dos votos. Mas, no momento seguinte ao triunfo do novo regime, como conciliar, evitando fracturas e conflitos, ordens e razões diferentes, a razão de estado e a religião, a ordem da polis e a família, o interesse colectivo e os laços individuais? É sobre esta tensão política, de que Antígona e Filoctetes são exemplos modelares, como se de uma substância vulcânica se tratasse, que, de um modo geral, o teatro de Sófocles se constrói. Não espanta por isso que as suas tragédias sejam as tragédias do herói solitário, do distinto homem sobre quem, privilegiada e tragicamente, cai o destino de eleição, Antígona ou Electra, Ájax ou Édipo, Dejanira ou Héracles ou Filoctetes. E esta dificuldade política, desenhada em contornos tão individuais, toca-nos imediatamente, envolvendo o nosso enraizado individualismo, desocultando a astenia da nossa vida colectiva, as dúvidas e obscuridades na elucidação dos princípios que a orientam e a regem, a obliquidade na nossa pessoal inserção na causa comum. Seria boçal erro restringir este perfil político do teatro de Sófocles, que tão bem nos engloba e logo nos adopta, a um limitado "jogo da política", a um estrito desejo do poder, à intensa sedução por este exercida, barca de devaneios que navega sobre um mar de intrigas e traições. É que o cenário da polis, o universo da política em Sófocles é imensamente mais vasto e mais profundo que a simples ambição pelo poder; esta está presente, mas como capa exterior dos dilaceramentos da nossa vida familiar e colectiva, e, mesmo estas, determinadas pelas limitações da nossa condição de seres finitos, súbditos da ignorância, da força dos enganos, dos equívocos, da morte. E não é tanto esse hálito político, mas essa outra coisa, autêntica e decisiva, que não está divorciada da "política" mas é mais do que ela, que faz Sófocles dobrar os séculos, desafiando os limites do nosso olhar.

As comemorações do nascimento do autor de Rei Édipo integraram debates, exposições, teatro e cinema. A obra de Sófocles foi comentada e analisada a partir de diversos pontos de vista. Carlos Miralles (Universidade de Barcelona), Freddy Decreus (Universidade de Gand) e Maria de Fátima Sousa e Silva (Universidade de Coimbra) debruçaram-se sobre a modernidade do poeta, a diversidade da sua presença na cena contemporânea, a sua permanência na nossa memória cultural, apresentando comunicações intituladas, respectivamente, "Sófocles como poeta en el siglo XX", "Sófocles na cena contemporânea" e "Sentido da permanência e risco de esquecimento de Sófocles: um convite à leitura". Numa análise ampla, abarcando globalmente a obra do tragediógrafo, Richard Hunter (Cambridge) e José Pedro Serra (Universidade de Lisboa), procurando identificar alguns dos temas e dos traços característicos do teatro sofocliano, falaram sobre a "Temática sofocliana" e sobre a "Construção do trágico em Sófocles", respectivamente. Maria do Céu Fialho (Universidade de Coimbra) centrou-se nos estásimos, os elementos líricos das tragédias, discorrendo sobre " 0 perfil dos coros em Sófocles". Ainda sobre a perenidade de Sófocles uma mesa redonda reuniu Maria do Céu Fialho (sobre a tradução), Luís Navarro (sobre a produção) e Hélia Correia (sobre a reescrita), autora de uma Antigona. A presença de Sófocles na ópera foi também abordada por J. M. de Bustamante (Universidade de Santiago de Compostela) que apresentou uma comunicação intitulada "Sófocles na ópera". A relação entre Sófocles e o cinema foi também explorada e muitos foram os oradores que incidiram sobre este tema; estas foram as intervenções: Jorge Silva Melo/Francisco Frazão, "Linguagem cinematográfica e teatro sofocliano: contrapontos - presenças e ausências clássicas no cinema"; João Bénard da Costa, "Do mito ao cinema"; Pedro I. Cano (Universidade de Barcelona), "Aspectos de la obra de Sófocles en el cine". Aguarda-se a publicação das Actas, nas quais, pelo muito interesse que sempre revestem, muito se desejaria estivesse incluido o texto de Luís de Sousa Rebelo ("Os Maias em leitura sofocliana") que, por motivos de força maior, não pôde ser apresentado em devida altura.

Completando a abordagem teórica sobre as relações entre Sófocles e o cinema, graças à colaboração com a Cinemateca Portuguesa foram projectados alguns filmes de temática sofocliana: Oedipe Roi de André Calmettes, França -1908, Édipo de G. de Liquoro, Itália - 1910, Electra de J. S. Blankton, USA - 1910, La Nouvelle Antigone de Jacques de Baroncelli, França - 1916, Electra de Michael Cacoyannis, 1961, Édipo Reide Pier Paolo Pasolini, Édipo Reide Philip Saville, Antigona de Yorgos Javelis, 1961, Édipo de Toishiro Narushima, Japão - 1986, Antigona de Danielle Huillet/Jean Marie Straub, Apontamentos para uma Oresteia africana de Pier Paolo Pasolini, Secrète Defense de Jacques Rivette, Mourning becomes Electra de Dudley Nichols a partir da peça de O'Neill, Fedra de Manuel Mur Oti, Vaghe Stelle dell' Orsa de Luchino Visconti. Para televisão, puderam ainda ser vistos Antígona (1984) e Édipo em Colono (1985) de Don Taylor.

Uma exposição de Máscaras de Tragédia, organizada pelo FESTEA (Festival de Teatro de Tema Clássico) e a representação de As Traquínias pelo Thíasos - grupo do Instituto de Estudos Clássicos que ciclicamente leva à cena peças do reportório clássico -, com encenação de Delfim Leão e direcção de Victor Torres, completaram o conjunto de actividades programadas.

E embora não fizesse propriamente parte do programa das celebrações dos 2500 anos do nascimento de Sófocles, mas coincidindo no espírito, merece o maior destaque a publicação (Minerva, Coimbra, 2003), num único volume, das sete tragédias de Sófocles que chegaram até nós, com traduções a partir do grego de Maria Helena da Rocha Pereira, Maria do Céu Fialho e José Ribeiro Ferreira. Além de reunir as traduções já existentes, mas dispersas, Antígona, As Traquínias, Rei Édipo, Filoctetes e Édipo em Colono, este volume contém ainda as traduções inéditas do Ájax e da Electra, da responsabilidade de Maria Helena da Rocha Pereira e Maria do Céu Fialho, respectivamente. E assim, também em português, e numa tradução digna de crédito, prossegue Sófocles o seu, nosso, caminho. 